\title{
BMJ Open Assessment of the advantage of the serum S100B protein biomonitoring in the management of paediatric mild traumatic brain injury - PROS100B: protocol of a multicentre unblinded stepped wedge cluster randomised trial
}

\author{
Damien Bouvier, ${ }^{1}$ David Balayssac, ${ }^{2}$ Julie Durif, ${ }^{3}$ Charline Mourgues, ${ }^{4}$ \\ Catherine Sarret, ${ }^{5}$ Bruno Pereira, ${ }^{4}$ Vincent Sapin ${ }^{1}$
}

To cite: Bouvier D, Balayssac D, Durif $\mathrm{J}$, et al. Assessment of the advantage of the serum S100B protein biomonitoring in the management of paediatric mild traumatic brain injury—PROS100B: protocol of a multicentre unblinded stepped wedge cluster randomised trial. BMJ Open 2019;9:e027365. doi:10.1136/ bmjopen-2018-027365

- Prepublication history and additional material for this paper are available online. To view these files, please visit the journal online (http://dx.doi. org/10.1136/bmjopen-2018027365).

Received 19 0ctober 2018 Revised 14 February 2019 Accepted 29 March 2019

D Check for updates

(c) Author(s) (or their employer(s)) 2019. Re-use permitted under CC BY-NC. No commercial re-use. See rights and permissions. Published by BMJ.

For numbered affiliations see end of article.

\section{Correspondence to}

Dr Damien Bouvier:

dbouvier@chu-clermontferrand. $\mathrm{fr}$

\section{ABSTRACT}

Introduction S100B serum analysis in clinical routine could reduce the number of cranial CT (CCT) scans performed on children with mild traumatic brain injury (mTBl). Sampling should take place within 3 hours of trauma and cut-off levels should be based on paediatric reference ranges. The aim of this study is to evaluate the utility of measuring serum $\mathrm{S} 100 \mathrm{~B}$ in the management of paediatric $\mathrm{MTBI}$ by demonstrating a decrease in the number of CCT scans prescribed in an S100B biomonitoring group compared with a 'conventional management' control group, with the assumption of a $30 \%$ relative decrease of the number of CCT scans between the two groups.

Methods and analysis The protocol is a randomised, multicentre, unblinded, prospective, interventional study (nine centres) using a stepped wedge cluster design, comparing two groups (S100B biomonitoring and control). Children in the control group will have CCT scans or be hospitalised according to the current recommendations of the French Society of Paediatrics (SFP). In the S100B biomonitoring group, blood sampling to determine serum S100B protein levels will take place within 3 hours after $\mathrm{mTBI}$ and subsequent management will depend on the assay. If $\mathrm{S} 100 \mathrm{~B}$ is in the normal range according to age, the children will be discharged from the emergency department after 6 hours' observation. If the result is abnormal, CCT scans or hospitalisation will be prescribed in accordance with current SFP recommendations. The primary outcome measure will be the proportion of CCT scans performed (absence/presence of CCT scan for each patient) in the 48 hours following mTBI.

Ethics and dissemination The protocol presented (Version 5, 03 November 2017) has been approved by the ethics committee Comité de Protection des Personnes sud-est 6 (first approval 08 June 2016, IRB: 00008526). Participation in the study is voluntary and anonymous. The study findings will be disseminated in international peer-reviewed journals and presented at relevant conferences.

Trial registration number NCT02819778.
Strengths and limitations of this study

The PROS100B trial is the first large-scale interventional study on the interest of serum S100B protein determination in the management of paediatric mild traumatic brain injury.

- A stepped wedge cluster design will be used involving sequential serum assay of $\mathrm{S} 100 \mathrm{~B}$ use in clusters of participant centres. As more clusters are exposed to the intervention in a stepped wedge cluster design towards the end of the study than in its early stages, there is a risk that the effect of the intervention might be confounded with underlying temporal trends. However, the statistical analysis is intended to encompass the assessment of this temporal effect.

- The unblinded design of the study may lead to a contamination bias during the control period during which the investigators may seek to improve their performance, and to an information bias related to physicians assessing outcomes by knowing the time period of the study. Nevertheless, a learning curve analysis will be performed to evaluate if an improvement in terms of primary outcome is observed over time. This effect will be analysed using Bayesian hierarchical models to adjust the trial results in the case of a learning curve effect.

\section{BACKGROUND}

The incidence of traumatic brain injury (TBI) in children is high (691 per 100000 in emergency departments), and TBI constitutes a leading public health problem. ${ }^{12}$ Mild TBI (mTBI), defined according to the Glasgow Coma Scale (GCS) from 13 to $15,{ }^{3}$ is one of the most common causes of paediatric hospital admission. ${ }^{45}$ Children with mTBI account for $5 \%-8 \%$ of visits to French 
paediatric emergency departments (60-100 per 100000 children). ${ }^{6}$

Cranial CT (CCT) is a standard diagnostic tool for adults with TBI. In children, however, several recent large-scale epidemiological studies have described a link between radiation exposure from CCT scans and the risk of future cancer. ${ }^{7-9}$ An Australian study of 11 million children found a $24 \%$ (relative risk 2.44) increase in cancer risk for the 680000 children who underwent CT scanning (including 59\% CCT scans) and a 35\% (relative risk 3.24) increase in the age group 1-4years. ${ }^{8}$

Alternatively, children can be admitted for inpatient observation with CCT scans performed only on those with clinical deterioration. This approach reduces X-ray exposure but is more costly than using CCT scans for initial diagnosis. ${ }^{10} 11$ However, most CCT scans and inpatient observations could be avoided, since 93\%- $100 \%$ according to the studies of children suffering from mTBI have no intracerebral lesions. ${ }^{12}$ In this context, clinical decision rules were developed to help clinicians identify children showing a very low risk of developing intracerebral lesions. ${ }^{13}$ Clinical prediction rules were first validated by the Pediatric Emergency Care Applied Research Network (PECARN) algorithm in a prospective cohort. ${ }^{14}$ The application of the PECARN algorithm for children with mTBI leads to beneficial management and more cost-effective care. ${ }^{15}$ More recently, Scandinavian guidelines for the initial management of mTBI in children were published but must be validated before extensive clinical use. ${ }^{16}$ The PECARN strategy suggests an algorithm in which children with mTBI can be divided into three risk categories (very low, intermediate and high risk) according to their risk of developing clinically severe brain injuries, which directly impacts decision-making regarding CCT scanning. The American study ${ }^{14}$ strongly advocated the recommendations for mTBI management issued by the French Society of Emergency Medicine ${ }^{6}$ and the French Society of Paediatrics (SFP). ${ }^{17} 18$ This algorithm decreased by $10 \%$ the use of CCT scans for all three risk categories. ${ }^{13}$

The use of biomarkers is a supplementary tool for identifying patients at risk of intracerebral lesions who might need imaging. Serum S100B protein is well established as a sensitive biomarker in TBI. S100B is one of the calcium-binding proteins found in glial cells. It is a small dimeric cytosolic protein $(21 \mathrm{kDa})$ involved in a variety of intracellular and extracellular regulatory activities. $^{19}{ }^{20}$ After cerebral lesions, S100B is immediately released from damaged glial cells into the blood (detection 30 min after trauma) and eliminated by the kidney. It has a short half-life of about $30-100 \mathrm{~min} .{ }^{21-23}$ The potential of serum S100B in reducing unnecessary CCT scans in adults presenting mTBI has been well established in many observational studies ${ }^{24-27}$ and confirmed by two interventional studies. ${ }^{28}{ }^{29}$ The addition of serum S100B to the Scandinavian guidelines for mTBI management decreased the need for CCT scans in adults by one-third, with a significant cost reduction. ${ }^{29}{ }^{30}$ Undén et al described these findings in a meta-analysis of adults with mTBI and voiced the need for more studies in children. ${ }^{31}$ Further efforts should focus on standardising serum S100B interpretation in this paediatric population, using specific references ranges. ${ }^{16}$ Although some studies have reported data from children with mTBI. ${ }^{32-36}$ A recent meta-analysis demonstrated the usefulness of serum S100B as a biomarker in the management of paediatric mTBI while emphasising that a large multicentre study is missing for this population. ${ }^{37}$

In this context, the primary objective of our study is to evaluate the performance of serum S100B measurement in the management of paediatric mTBI by demonstrating a decrease in the proportion of CCT scans prescribed in an S100B biomonitoring group compared with a control group ('conventional management'), with the assumption of a $30 \%$ relative decrease in the number of CCT scans between the S100B biomonitoring and control groups. The secondary objectives are to demonstrate the utility of serum S100B measurement with regards to the time spent in the paediatric emergency room, hospitalisations, radiation exposure, sedation and sedative use, the detection of complications (intracranial lesions) by CCT scan, which can occur at a rate of $0 \%-7 \%$ in patients with $\mathrm{mTBI}$, the absence of late side effects at 48 hours and 3 weeks after mTBI, and the compliance of emergency physicians with the S100B assay, and lower management costs.

\section{METHODS AND ANALYSIS \\ Study settings}

This multicentre study will be performed in nine French University Hospital Centres (Clermont-Ferrand, Limoges, Lyon, Marseille, Montpellier, Nice, Reims, Saint-Etienne and Nîmes). The sponsor of the study will be the University Hospital Centre of Clermont-Ferrand. The inclusions period runs from November 2016 to the end of March 2020.

\section{Study design}

This is a diagnostic prospective, randomised, controlled, unblinded multicentre study using a stepped wedge cluster design, in which paediatric patients (aged $\leq 16$ years) presenting with mTBI in the paediatric emergency room with a GCS score of 15 will benefit from usual care ('conventional management') in the control group, and from S100B result-related clinical management in the S100B biomonitoring group.

A recent systematic review indicated that stepped wedge cluster randomised design is used in particular 'to evaluate interventions during routine implementation, particularly for interventions that have been shown to be effective in more controlled research settings, or where there is lack of evidence of effectiveness but there is a strong belief that they will do more good than harm'. ${ }^{38}$ A stepped wedge cluster-randomised controlled design allows delivering the interventions sequentially to all trial clusters over a number of time periods. The order in which 


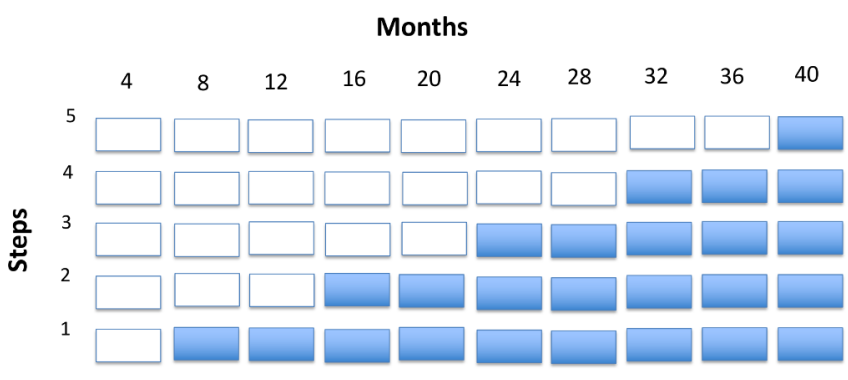

Conventional management control group S100B biomonitoring group

Figure 1 Stepped wedge study design. the clusters receive interventions is randomised, and by the end of the study all the clusters will have adopted the interventions. Centres will be randomly allocated to a step by the study's statistician using a block randomisation sequence generated in Stata V.13. The step constitution is stratified according to the planned recruitment of each participating centre. Ten intervals of 4 months will be fixed over 40 months. The randomisation will involve five steps for which two centres will be included in the following steps 1, 2, 4 and 5, and one centre in step 3 (figure 1). The children in the control group will receive conventional management treatment in accordance with the SFP recommendations (figure 2). Patients in the S100B biomonitoring group will have a single

\section{A Children $<2$ years}

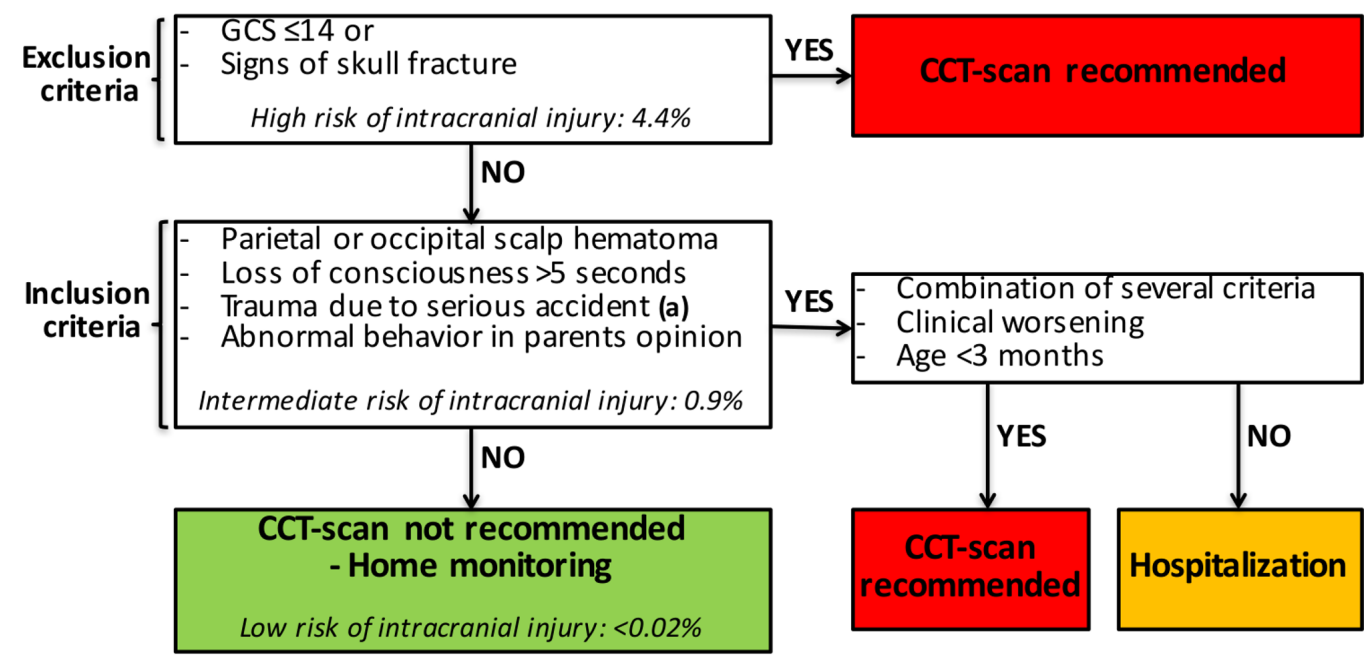

\section{B Children between 2 and 16 years}

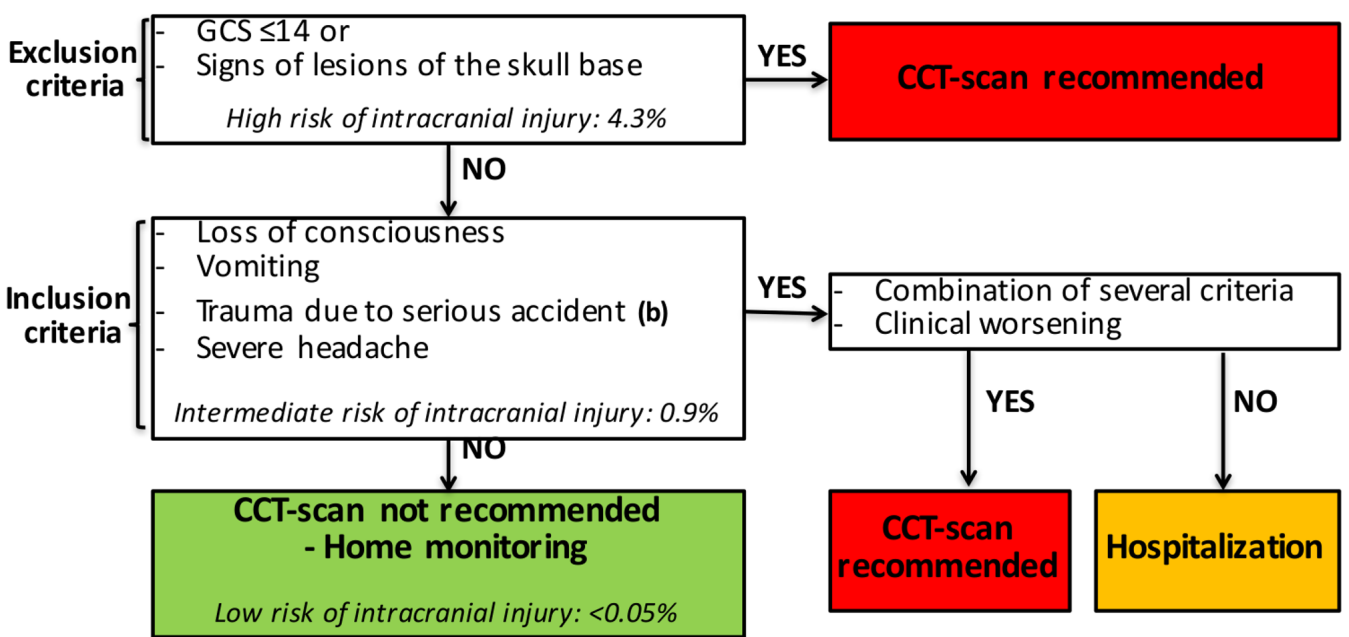

Figure 2 Decision algorithm for CCT scan or hospitalisation indication for children with mild traumatic brain injury management in the 'conventional management' control group. (a) Criteria of serious accident for children under 2 years old: road accident with passenger ejected from vehicle or death of another person or rollover; pedestrian hit by a moving vehicle; cyclist not wearing a helmet; fall from a height greater than $0.9 \mathrm{~m}$. (b) Criteria of serious accident for children over 2 years old: road accident with passenger ejected from vehicle or death of another person or rollover; pedestrian hit by a moving vehicle; cyclist not wearing a helmet; fall from a height over 1.5 m. CCT, Cranial CT; GCS, Glasgow Coma Scale. 


\section{A Children $<2$ years}

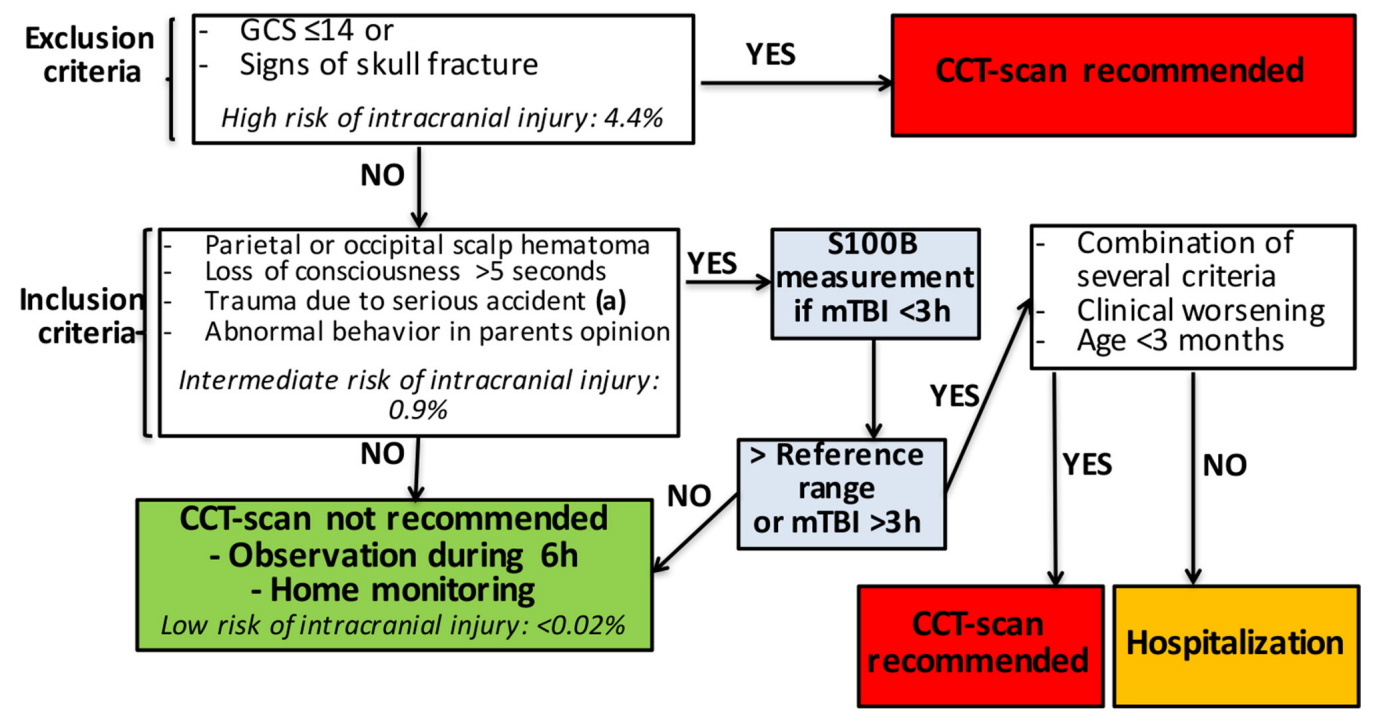

\section{B Children between 2 and 16 years}

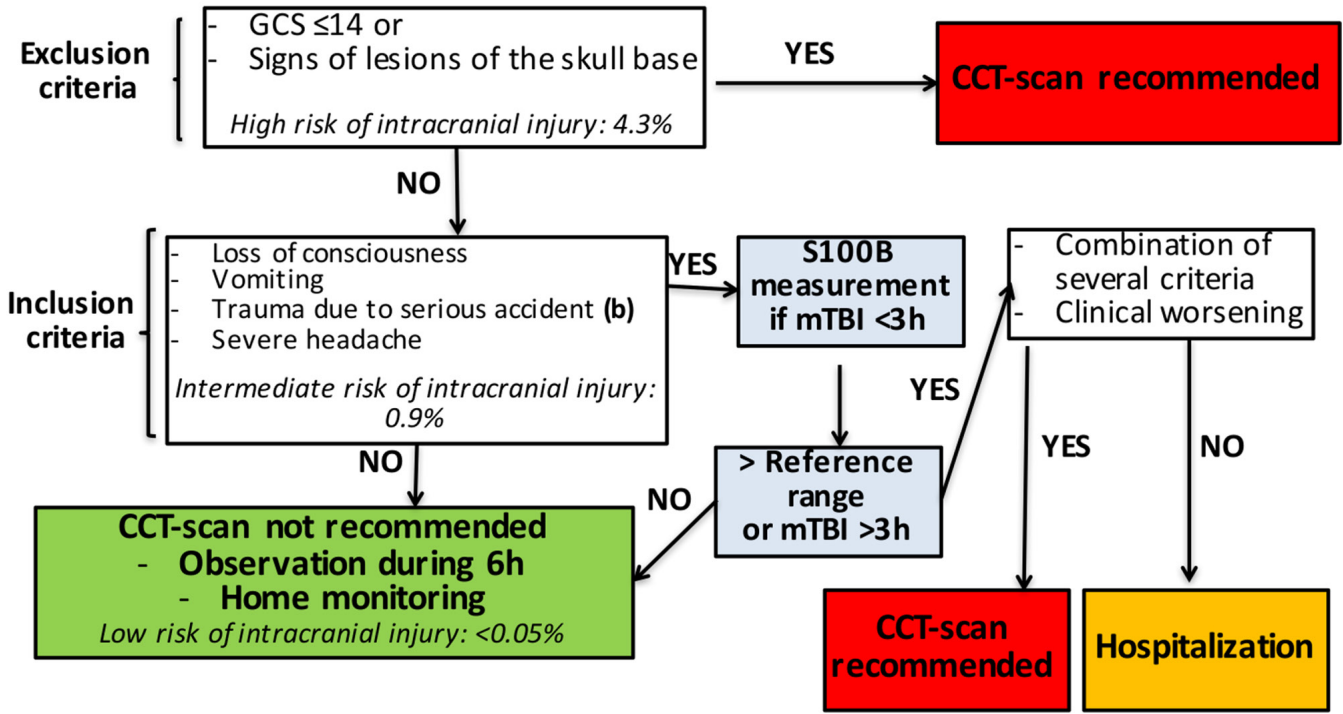

Figure 3 Decision algorithm for CCT scan or hospitalisation indication for children with mTBI management in the S100B biomonitoring group. (a) Criteria of serious accident for children under 2 years old: road accident with passenger ejected from vehicle or death of another person or rollover; pedestrian hit by a moving vehicle; cyclist not wearing a helmet; fall from a height $>0.9 \mathrm{~m}$ ). (b) Criteria of serious accident for children over 2 years old: road accident with passenger ejected from vehicle or death of another person or rollover; pedestrian hit by a moving vehicle; cyclist not wearing a helmet; fall from a height over 1.5 m. CCT, Cranial CT; GCS, Glasgow Coma Scale; mTBI, mild traumatic brain injury.

blood sample drawn by a micromethod ( $1 \mathrm{~mL}$ of blood) for S100B determination within 3 hours after trauma, and their subsequent management will depend on the S100B assay results. Children with positive tests will receive conventional management treatment in accordance with the SFP recommendations. ${ }^{17}$ In the case of a negative test, the children will be discharged from the emergency department after 6hours' observation (figure 3).

Physicians will include patients after information and obtain a signed consent form from parents. Research associates will enter the data into the electronic case report form (eCRF). The presence of persistent clinical signs 48 hours and 3 weeks after mTBI will be monitored by the clinical research associates for the two groups by telephone calls. Other hospitalisations will be also sought in the patient' file. Overall, this will be a 41-months study (40 months of inclusion +1 month for the follow-up of the last patients included).

\section{Eligibility}

The study population comprises paediatric patients (aged $\leq 16$ years) admitted to paediatric emergency departments for mTBI with a GCS of 15 requiring hospitalisation and/or CCT scan as per SFP recommendations. The 
GCS will be used to evaluate children older than 2 years while the paediatric GCS was assessed in non-verbal children younger than 2 years. ${ }^{39}$

\section{Inclusion criteria}

- Age $\leq 16$ years.

- Management within 3 hours after TBI (for blood sampling).

- GCS score of 15 classically requiring hospitalisation and/or CCT scan as per SFP recommendations (figures 2 and 3 ). ${ }^{17}$ These criteria are for children aged under 2 years: parietal or occipital scalp haematoma, loss of consciousness for more than $5 \mathrm{~s}$, trauma due to serious accident (road accident with passenger ejected from vehicle or death of another person or rollover, pedestrian hit by a moving vehicle, cyclist not wearing a helmet, fall from a height superior to $0.9 \mathrm{~m}$ ), abnormal behaviour in the opinion of parents. For children aged over 2 years, the criteria are: loss of consciousness at time of accident, vomiting, trauma due to serious accident (road accident with passenger ejected from vehicle or death of another person or rollover, pedestrian hit by a moving vehicle, cyclist not wearing a helmet, fall from a height of more than $1.5 \mathrm{~m}$ ) and severe headache.

\section{Exclusion criteria}

- Patient already enrolled in another therapeutic trial with drug administration.

- Down's syndrome, melanoma.

- Refusal of child, parents or legal guardian.

- Trauma occurring more than 3 hours previously.

- GCS score of 13 or 14 , or signs of skull fracture or lesions of the skull base (CCT scan recommended) (figures 2 and 3).

- Children with TBI not requiring hospitalisation and/ or CCT scan as per SFP recommendations (figures 2 and 3$).^{17}$

\section{Consent}

The patients and the parents or legal guardians will be fully and sincerely informed in understandable language of the objectives and constraints of the study, the potential risks, the observation required and safety measures, and of their right to refuse to participate in the study and the possibility to revoke their consent at any time. The investigator must also inform the subjects of the ethics committee's opinion.

All this information appears in an information notice and consent form (online supplementary file 1) given to the patient. The free, informed and written consent of the patient, when given, will be collected by the investigator. These documents are approved by the competent ethics committee and are to be used for the study in question, to the exclusion of any other document.

Two original copies will be co-signed by both the investigator, the patient and the parents or legal guardian. The second copy will be filed in the patient's medical record.

\section{Outcome measures}

The primary endpoint is the proportion of CCT scans prescribed (absence/presence of CCT scan for each patient) within 48 hours following TBI, compared between the two groups (S100B biomonitoring group vs 'conventional management' control group).

The secondary endpoints are duration of management defined by the time spent in the paediatric emergency department (time between emergency room admission and discharge), duration of hospitalisation in another hospital department for observation, effective radiation dose $(\mathrm{mSv})$ for each CCT scan, sedation and quantity of sedatives prescribed, presence of intracranial injury on CCT scan, presence of persistent clinical signs at the telephone follow-up interview 48 hours and 3 weeks after the mTBI, and the proportion of positive/negative CCT scans in each group, and cost of management. Data collected are summarised in table 1. Presence of persistent clinical signs is appraised over 48 hours and 3 weeks after mTBI. They were defined by the following clinical symptoms: vomiting, facial paralysis, movement disorders, vertigo, photomotor reflex disorder, seizure, progressive headache or behaviour change. The presence of these signs is sought in the file of the child in case of hospitalisation. Specific hospitalisation in neurosurgery or intensive care unit is also sought. The patients who are not hospitalised will be followed for 48 hours and 3 weeks after consultation, with a standardised telephone interview led by a clinical research associate. The following items will be collected in all participating children: frequency of vomiting since returning home; problems or difficulties related to arms or legs movements observed by parents, convulsions, ocular discomfort, any changes in facial expression, parental opinion of child's return to the previous state of health before the consultation or changes that had been observed. For the children aged over 4 years, additional information will be collected regarding complaints of headaches.

\section{S100B assay}

The analytical method used in the study is based on an electrochemiluminescence assay (Roche Diagnostics instruments). Its analytical performance (coefficient of variation of $3.1 \%$ ) requires only a single determination without risk of analytical error. The test sample volume $(20 \mu \mathrm{L})$ and dead volume $(150 \mu \mathrm{L})$ are suitable for the type of blood sampling (micromethod) chosen to be least traumatic to the children. The S100B serum assay will be considered positive according to age: $0-9$ months: $>0.35 \mu \mathrm{g} / \mathrm{L}, 9-24$ months: $>0.23 \mu \mathrm{g} / \mathrm{L}$ and $>24$ months: $>0.18 \mu \mathrm{g} / \mathrm{L}^{40}$

\section{Sample size estimation}

The proportion of CCT scans ordered during conventional management of mTBI is roughly $20 \%$ (between $10 \%$ and $30 \%) .{ }^{40}$ Thus, to show a $6 \%$ difference between the two groups, ie, a $30 \%$ relative reduction ${ }^{40}$ in the rate of CCT scans prescribed in the S100B biomonitoring 
Table 1: Data collected. The information in the table will be recorded on the case report form for each patient

\begin{tabular}{|c|c|}
\hline Information & Data collected \\
\hline $\begin{array}{l}\text { Group in the study in which } \\
\text { the child is included }\end{array}$ & Control or S100B biomonitoring. \\
\hline Information about the mTBI & $\begin{array}{l}\text { Type of accident. } \\
\text { Date and time of mTBI. } \\
\text { GCS score at arrival at emergency department. } \\
\text { Clinical signs: } \\
\text { - presence }(+) \text { or absence }(-) \text { of signs of impaired consciousness. } \\
\text { - presence }(+) \text { or absence }(-) \text { of signs of skull fracture. } \\
\text { - presence }(+) \text { or absence }(-) \text { of signs of fracture of skull base. } \\
\text { - presence }(+) \text { or absence }(-) \text { of parietal or occipital scalp hematoma. } \\
\text { - presence }(+) \text { or absence }(-) \text { of loss of consciousness for more than } 5 \text { s in children under } \\
\text { - } 2 \text { years old. } \\
\text { - Presence }(+) \text { or absence }(-) \text { of serious accident. } \\
\text { - old. } \\
\text { - Presence }(+) \text { or absence }(-) \text { of immediate loss of consciousness in children over } 2 \text { years }(-) \text { of vomiting in children over } 2 \text { years old. } \\
\text { - under } 2 \text { years old. } \\
\text { - Presence }(+) \text { or absence }(-) \text { of severe headache in children over } 2 \text { years old. }\end{array}$ \\
\hline $\begin{array}{l}\text { Information related to serum } \\
\text { S100B assay }\end{array}$ & $\begin{array}{l}\text { Date and time of blood sampling (time between mTBI and blood sampling). } \\
\text { Serum S100B concentration in } \mu \mathrm{g} / \mathrm{L} \text {. } \\
\text { Concentration higher }(+) \text { or lower }(-) \text { than age-related reference value. }\end{array}$ \\
\hline $\begin{array}{l}\text { Information from the follow-up } \\
\text { at } 48 \text { hours and } 3 \text { weeks post- } \\
\text { mTBl: positive }(+) \text { or negative } \\
\text { (-) answer to the standardised } \\
\text { questions }\end{array}$ & $\begin{array}{l}\text { Number of vomiting. } \\
\text { Presence }(+) \text { or absence }(-) \text { of headache in children over } 2 \text { years old. } \\
\text { Presence }(+) \text { or absence }(-) \text { of convulsion. } \\
\text { Presence }(+) \text { or absence }(-) \text { of motor deficit. } \\
\text { Presence }(+) \text { or absence }(-) \text { of facial paralysis. } \\
\text { Presence }(+) \text { or absence }(-) \text { of abnormal behaviour. } \\
\text { Presence }(+) \text { or absence }(-) \text { of abnormal photomotor reflex. }\end{array}$ \\
\hline $\begin{array}{l}\text { Information related to the cost } \\
\text { of management }\end{array}$ & $\begin{array}{l}\text { S100B monitoring. } \\
\text { CCT scan. } \\
\text { Hospitalisation by departments and other later hospitalisation. }\end{array}$ \\
\hline
\end{tabular}

CCT, cranial computer tomography; GCS, Glasgow Coma Scale; ICU, intensive care unit; mTBI, mild traumatic brain injury.

group compared with the control group, a sample of 615 subjects per group is required using an individual randomised design, a two-sided type I error at $5 \%$ at a statistical power of $80 \%$. Furthermore, in light of the publication of Calcagnile $e t a l$, it is expected that $30 \%$ of physicians treating patients in the S100B biomonitoring group will not be based on their practice on the result of the serum S100B assay. ${ }^{28}$ Thus, 800 subjects will be enrolled per group, to conserve a power of $80 \%$ with the hypotheses defined previously. ${ }^{41}$ The assumption in randomised controlled trials that the outcome of an individual patient is completely unrelated to that of any other patient is violated in cluster randomised trials as patients within any one cluster (centre in our case) are more likely to respond 
in a similar manner. This similarity is known as the intraclass correlation coefficient (ICC). Because of this lack of independence, larger sample sizes are required. The ICC values usually described in the literature ${ }^{42}$ and reported by the University of Aberdeen on a database dedicated to ICC (https://www.abdn.ac.uk/hsru/what-we-do/tools/ index.php), range between 0.005 and 0.05 . According to these considerations, and in view of the randomisation sequence, time periods, average number of patients per centre, coefficient of variation of cluster size defined as the ratio of the SD of cluster sizes, ${ }^{43}$ and lost to follow-up (around 5\%), 4000 patients ( $\mathrm{n}=2000$ patients by group) will be needed. Every trimester, a newsletter will be sent to each participating centre to present the inclusion rate and encourage inclusions of patients. To estimate sample size, Stata routine stepped wedge developed by Hemming and Girling ${ }^{44}$ is used.

An interim analysis is planned after the enrolment of 2000 patients to estimate the statistical power according to the ICC and absolute difference observed. The possible decision to stop the study will be planned considering a type I correction.

\section{Statistical analyses}

Analyses will be performed using Stata V.13. All the data will be analysed by intention to treat. The tests will be two-sided, with a type I error set at $\alpha=0.05$. Baseline characteristics (centres and patients) will be presented as the mean and standard deviation or the median and interquartile range for each randomisation group for continuous data, and as the number of patients and associated percentages for categorical parameters. The characteristics of the patients and clusters will be summarised by randomisation group to allow considering selection biases and lack of balance. Patients will be described and compared between randomised groups at baseline for eligibility, and epidemiological, clinical and treatment characteristics. Protocol deviations and reasons for withdrawal will be described. Other parameters such as the numbers analysed, average cluster size, cluster characteristics and important patient characteristics will be compared in each cluster by period. To compare the proportion of CCT scans prescribed, a generalised linear mixed model (robust Poisson) will be proposed. Randomisation groups, randomisation steps, time and their interactions will be evaluated as fixed effects and centre and time as random effect. Results will be expressed as relative risks and $95 \%$ confidence intervals. The estimated intracluster correlation and time effect from the fitted model will be reported.

Multivariable analysis will use the same statistical model with covariates determined according to the univariate results and clinical relevance (age groups defined by age-related S100B cut-off values). Furthermore, particular attention will be paid to between and within physician variability in decision-making regarding the primary endpoint. As it is difficult to know if physician and centre effects will be not nested and confounding, physician within centre will be treated as a random effect in a sensitivity analysis. The comparisons between the two groups for other endpoints will be performed using the same random-effects models, taking into account between and within centre variability: linear (duration of management, duration of hospitalisation, effective radiation dose, quantity of sedatives prescribed; if necessary, logarithmic transformation to obtain the normal distribution will be envisaged) or generalised linear (sedation yes/no, presence of intracranial lesions on CCT scans, presence of persistent clinical signs at the telephone interview). The random-effects models will also be used to study longitudinal repeated data (48hours and 3 weeks) considering the patient as a random effect in addition to the centre. The statistical nature of missing data will be studied and a sensitivity analysis will be proposed to analyse the impact of missing data on the results and to propose the most appropriate method of imputation.

Finally, according to the design of the study, a sensitivity analysis will be conducted with hospital (cluster) as the main unit of analysis. Usual statistical tests (Student, Mann-Whitney, $\mathrm{X}^{2}$ ) will be applied.

\section{Economic analyses}

The main objective of the economic analysis will be to measure and compare costs in the two groups.

We choose to perform a cost minimisation analysis because the clinical endpoint is the same for both the intervention and the control group. The protein S100B blood test enables caring for the patient appropriately, detecting TBI earlier and avoiding performing unnecessary CCT scans. The cost analysis will be performed from the standpoint of a University Hospital. Our study will focus on the analyses of care costs and avoided costs in each group. French hospital financing is based on a pricing scale for all current forms of medical care (fee for service). When an innovative medical treatment is developed, the financing system is temporarily based on grants. We hypothesise that the financing system for innovative medical care will finance the protein S100B blood test and that the price will be close to the future price outside the contractual pricing scale of the French health system. Considering the French pricing system, if the number of CCT scans performed for cranial trauma decreases due to introduction of protein S100B blood test in the investigation of mTBI, the hospital might lose income. However, according to the waiting time for this exam and public/ private competition, we hypothesise that income will remain stable as each avoided CCT scan will be replaced by another one, irrespective of the medical indication. Costs will be analysed by microcosting during the standard follow-up of 3 weeks planned in the study: the costs of S100B monitoring, costs of the CCT scans including medical costs if children are under sedation during the CCT scan, and costs of hospitalisation by departments and other later hospitalisations. Therefore, the cost analysis focuses on avoided costs thanks to the introduction of protein S100B blood test. We will not consider other 
consequences such as the impact of decreased delay in care, the decrease of radiation withdrawal effects by reducing inappropriate CCT scans or the lower risk of healthcare associated infections due to shorter lengths of stay.

\section{Study monitoring}

The study coordinators will ensure that the study is conducted in accordance with Good Clinical Practice through site monitoring visits. A monitoring protocol has been written and agreed prior to randomisation. A Clinical Research Associate designated by the sponsor will ensure the proper conduct of the study, the collection of data generated in writing, and their documentation, recording and reporting, as per the Standard Operating Procedures in effect at the University Hospital of Clermont-Ferrand and in compliance with Good Clinical Practices and the legislative and regulatory provisions in force.

For each centre, there is an implementation visit protocol, a monitoring visit per year and a closing visit at the end of the inclusions. The implementation visit protocol was made by the principal investigator (Damien Bouvier) and the main Clinical Research Associate (Julie Durif). They presented to the co-investigators the study using a PowerPoint support, brought the investigator file (with all the documents relating to the study) and provided the centre with forms (information notice, consent form, explanatory leaflets for physicians who will recruit participants). The monitoring visits will be conducted by the main Clinical Research Associate who will study patient's research files randomly and provide the centre with forms. All files will be monitored on the eligibility criteria, consent forms and primary endpoint. The closing visits will be conducted by the main Clinical Research Associate to ensure that participant inclusion is closed and archiving for 15 years of all documents related to the study.

Any new information concerning the study which may jeopardise the safety of the research subjects will be subjected to appropriate urgent measures (prompt and timely notification by the Sponsor to the competent authority and the ethics committee). The principal investigator is responsible for reporting all adverse events on the CRF. The only expected adverse effect is a risk of false negative results (expected to be low in view of the sensitivity and negative predictive value of the assay).

An independent monitoring committee will be set up, composed of a biochemist, a paediatrician and a methodologist. This committee will meet for the first time at study initiation and then throughout the duration of the study at its own initiative or at the sponsor's request. The committee will also issue a general opinion on the conduct of the study and can provide an opinion on decision-making related to premature study termination and substantial protocol amendments.

\section{Data management}

All the information required by the study protocol (table 1) will be recorded in an eCRF. Data will be collected and transcribed in a clear and legible manner in the eCRF. The eCRF will be developed and made accessible via the internet (SSL 128-bit SSL encryption). Access will be controlled by a personal password and all consultations and changes in the eCRF will be logged. The data will be entered in single input on the eCRF at each study centre. They will be stored on a secured web platform (Clinsight, Ennov Clinical, France) and be validated according to the data management plan established jointly between the principal investigator and the sponsor. Lastly, the data will be frozen/unfrozen according to standard procedures at Clermont-Ferrand University Hospital. All the data will be saved every night, kept for 4 weeks, then backed up on tape every month. Completion of the study is scheduled for December 2020.

\section{Patient and public involvement}

Patients and/or public were not involved in the research question and design of the study.

\section{ETHICS AND DISSEMINATION}

Important modifications to the protocol, such as modification of eligibility criteria, outcomes, analyses, investigator or centre must be validated by the competent authority and the ethics committee. After these approvals, the new protocol will be transferred to each participating investigator and centre. The data will only be disclosed after the preliminary joint agreement of the investigator and the sponsor. According to the sponsor agreement, the study findings will be disseminated in international peer-reviewed journals and presented at relevant conferences.

\section{Author affiliations \\ ${ }^{1}$ Biochemistry and Molecular Genetic Department, CHU Clermont-Ferrand, Université Clermont Auvergne, CNRS, INSERM, GReD, Clermont-Ferrand, France ${ }^{2} \mathrm{DRCl}$, CHU Clermont-Ferrand, Université Clermont-Auvergne, INSERM U1107, NEURO-DOL, Clermont-Ferrand, France \\ ${ }^{3}$ Biochemistry and Molecular Genetic Department, CHU Clermont-Ferrand, Clermont-Ferrand, France \\ ${ }^{4} \mathrm{DRCl}$, CHU Clermont-Ferrand, Clermont-Ferrand, France \\ ${ }^{5}$ Pediatric Department, CHU Clermont-Ferrand, Clermont-Ferrand, France}

Contributors VS and DBo designed the study, designed the trial and obtained ethical approval. JD and CS supervised the trial and data collection. BP provided statistical advice for the study design and analysed the data. DBa drafted the manuscript and all the authors substantially contributed to its revision. CM provided medico-economic advice for the study design.

Funding This study is funded by a grant from the French Ministry of Health (PHRC-15-188).

\section{Competing interests None declared.}

Ethics approval The protocol presented(version 5, 03 November 2017) has been approved by the ethics committee CPP (Comité de protection des personnes) sud-est 6 (first approval 08 June 2016, IRB:00008526). The study has been approved by the competent French authority (Agence Nationale de Sécurité du Médicament et des produits de santé, 28 April 2016, ID-RCB no 2016-A00195-46).

Provenance and peer review Not commissioned; externally peer reviewed. 
Open access This is an open access article distributed in accordance with the Creative Commons Attribution Non Commercial (CC BY-NC 4.0) license, which permits others to distribute, remix, adapt, build upon this work non-commercially, and license their derivative works on different terms, provided the original work is properly cited, appropriate credit is given, any changes made indicated, and the use is non-commercial. See: http://creativecommons.org/licenses/by-nc/4.0/.

\section{REFERENCES}

1. Thurman DJ. The epidemiology of traumatic brain injury in children and youths: A review of research since 1990. J Child Neurol 2016;31:20-7.

2. Trefan L, Houston R, Pearson G, et al. Epidemiology of children with head injury: a national overview. Arch Dis Child 2016;101:527-32.

3. Kristman VL, Borg J, Godbolt AK, et al. Methodological issues and research recommendations for prognosis after mild traumatic brain injury: results of the International Collaboration on Mild Traumatic Brain Injury Prognosis. Arch Phys Med Rehabil 2014;95:S265-S277.

4. Cassidy JD, Carroll LJ, Peloso PM, et al. Incidence, risk factors and prevention of mild traumatic brain injury: results of the WHO Collaborating Centre Task Force on Mild Traumatic Brain Injury. $J$ Rehabil Med 2004:28-60.

5. Schutzman SA, Greenes DS. Pediatric minor head trauma. Ann Emerg Med 2001;37:65-74.

6. Jehlé E, Honnart D, Grasleguen C, et al. Traumatisme crânien léger (score de Glasgow de 13 à 15) : triage, évaluation, examens complémentaires et prise en charge précoce chez le nouveau-né, l'enfant et l'adulte. Annales françaises de médecine d'urgence 2012;2:199-214.

7. Pearce MS, Salotti JA, Little MP, et al. Radiation exposure from CT scans in childhood and subsequent risk of leukaemia and brain tumours: a retrospective cohort study. Lancet 2012;380:499-505.

8. Mathews JD, Forsythe AV, Brady Z, et al. Cancer risk in 680,000 people exposed to computed tomography scans in childhood or adolescence: data linkage study of 11 million Australians. BMJ 2013;346:f2360.

9. Miglioretti DL, Johnson E, Williams A, et al. The use of computed tomography in pediatrics and the associated radiation exposure and estimated cancer risk. JAMA Pediatr 2013;167:700-7.

10. Norlund A, Marké LA, af Geijerstam JL, et al. Immediate computed tomography or admission for observation after mild head injury: cost comparison in randomised controlled trial. BMJ 2006;333:469.

11. Af Geijerstam JL, Britton M, Marké LA. Mild head injury: observation or computed tomography? Economic aspects by literature review and decision analysis. Emerg Med J 2004;21:54-8.

12. Homer CJ, Kleinman L. Technical report: minor head injury in children. Pediatrics 1999;104:e78.

13. Babl FE, Borland ML, Phillips N, et al. Accuracy of PECARN, CATCH, and CHALICE head injury decision rules in children: a prospective cohort study. Lancet 2017;389:2393-402.

14. Kuppermann N, Holmes JF, Dayan PS, et al. Identification of children at very low risk of clinically-important brain injuries after head trauma: a prospective cohort study. Lancet 2009;374:1160-70.

15. Nishijima DK, Yang Z, Urbich M, et al. Cost-effectiveness of the PECARN rules in children with minor head trauma. Ann Emerg Med 2015;65:72-80.

16. Astrand $R$, Rosenlund $C$, Undén J, et al. Scandinavian guidelines for initial management of minor and moderate head trauma in children. BMC Med 2016;14:33

17. Lorton F, Levieux K, Vrignaud B, et al. Actualisation des recommandations pour la prise en charge du traumatisme crânien léger chez l'enfant. Archives de Pédiatrie 2014;21:790-6.

18. Lorton F, Poullaouec C, Legallais $\mathrm{E}$, et al. Validation of the PECARN clinical decision rule for children with minor head trauma: a French multicenter prospective study. Scand J Trauma Resusc Emerg Med 2016;24:98

19. Donato R. S100: a multigenic family of calcium-modulated proteins of the EF-hand type with intracellular and extracellular functional roles. Int J Biochem Cell Biol 2001;33:637-68.
20. Zimmer DB, Cornwall EH, Landar A, et al. The $\mathrm{S} 100$ protein family: history, function, and expression. Brain Res Bull 1995;37:417-29.

21. Petzold A, Keir G, Lim D, et al. Cerebrospinal fluid (CSF) and serum S100B: release and wash-out pattern. Brain Res Bull 2003;61:281-5.

22. Jönsson $H$, Johnsson $P$, Höglund $P$, et al. Elimination of $S 100 B$ and renal function after cardiac surgery. $J$ Cardiothorac Vasc Anesth 2000;14:698-701.

23. Townend W, Dibble C, Abid K, et al. Rapid elimination of protein S-100B from serum after minor head trauma. J Neurotrauma 2006;23:149-55.

24. Biberthaler P, Linsenmeier U, Pfeifer KJ, et al. Serum S-100B concentration provides additional information fot the indication of computed tomography in patients after minor head injury: a prospective multicenter study. Shock 2006;25:446-53.

25. Ingebrigtsen $\mathrm{T}$, Romner $\mathrm{B}$, Marup-Jensen $\mathrm{S}$, et al. The clinical value of serum S-100 protein measurements in minor head injury: a Scandinavian multicentre study. Brain Inj 2000;14:1047-55.

26. Müller K, Townend W, Biasca N, et al. S100B serum level predicts computed tomography findings after minor head injury. $J$ Trauma 2007;62:1452-6.

27. Bouvier D, Oddoze C, Ben Haim D, et al. [Interest of S100B protein blood level determination for the management of patients with minor head trauma]. Ann Biol Clin 2009;67:425-31.

28. Calcagnile O, Undén L, Undén J. Clinical validation of $\mathrm{S} 100 \mathrm{~B}$ use in management of mild head injury. BMC Emerg Med 2012;12:13.

29. Undén L, Calcagnile O, Undén J, et al. Validation of the Scandinavian guidelines for initial management of minimal, mild and moderate traumatic brain injury in adults. BMC Med 2015;13:292.

30. Calcagnile $O$, Anell A, Undén J. The addition of S100B to guidelines for management of mild head injury is potentially cost saving. BMC Neurol 2016;16:200.

31. Undén J, Romner B. Can low serum levels of S100B predict normal CT findings after minor head injury in adults?: an evidence-based review and meta-analysis. J Head Trauma Rehabil 2010;25:228-40.

32. Filippidis AS, Papadopoulos DC, Kapsalaki EZ, et al. Role of the $\mathrm{S} 100 \mathrm{~B}$ serum biomarker in the treatment of children suffering from mild traumatic brain injury. Neurosurg Focus 2010;29:E2.

33. Schiavi P, Laccarino C, Servadei F. The value of the calcium binding protein $\mathrm{S} 100$ in the management of patients with traumatic brain injury. Acta Bio-Medica Atenei Parm 2012;83:5-20.

34. Mondello S, Schmid K, Berger RP, et al. The challenge of mild traumatic brain injury: role of biochemical markers in diagnosis of brain damage. Med Res Rev 2014;34:503-31.

35. Papa L, Ramia MM, Kelly JM, et al. Systematic review of clinical research on biomarkers for pediatric traumatic brain injury. $J$ Neurotrauma 2013;30:324-38.

36. Heidari K, Vafaee A, Rastekenari AM, et al. S100B protein as a screening tool for computed tomography findings after mild traumatic brain injury: Systematic review and meta-analysis. Brain Inj 2015;29:1146-57.

37. Oris C, Pereira B, Durif J, et al. The biomarker s100b and mild traumatic brain injury: A meta-analysis. Pediatrics 2018;141:141.

38. Mdege ND, Man MS, Taylor Nee Brown CA, et al. Systematic review of stepped wedge cluster randomized trials shows that design is particularly used to evaluate interventions during routine implementation. J Clin Epidemiol 2011;64:936-48.

39. Borgialli DA, Mahajan P, Hoyle JD, et al. Performance of the pediatric glasgow coma scale score in the evaluation of children with blunt head trauma. Acad Emerg Med 2016;23:878-84.

40. Bouvier D, Fournier M, Dauphin JB, et al. Serum S100B determination in the management of pediatric mild traumatic brain injury. Clin Chem 2012;58:1116-22.

41. Machin D. On the evolution of statistical methods as applied to clinical trials. J Intern Med 2004;255:521-8.

42. Adams G, Gulliford MC, Ukoumunne OC, et al. Patterns of intracluster correlation from primary care research to inform study design and analysis. J Clin Epidemiol 2004;57:785-94.

43. Eldridge SM, Ashby D, Kerry S. Sample size for cluster randomized trials: effect of coefficient of variation of cluster size and analysis method. Int J Epidemiol 2006;35:1292-300.

44. Hemming K, Girling A. A menu-driven facility for power and detectable-difference calculations in stepped-wedge clusterrandomized trials. Stata $J$ 2014;14:363-80. 